\title{
Real-Time Substructure Tests and Numerical Simulation of Mechanical Characteristics of Natural Rubber-Laminated Bearings
}

\author{
T. B. Peng, ${ }^{1}$ Y. H. Ni, ${ }^{2}$ and Y. C. $\mathrm{Wu}^{3}$ \\ State Key Laboratory of Disaster Reduction in Civil Engineering, Tongji University, Shanghai, China \\ 1 ptb@tongji.edu.cn \\ 2 1627380717@qq.com \\ 3 1630414@tongji.edu.cn
}

Natural rubber lamination is a kind of seismic isolation of bearings often used in civil engineering. The advantage of laminated bearings is large vertical stiffness and small lateral stiffness. In seismic regions, structural periods would be extended and the effect of seismic forces can be lowered using bearings. In previous tests, the static cyclic loading method was mainly used that failed to take account of the loading rate. The real-time substructure testing is proposed to simulate true seismic loads. This testing and test setup were first introduced, and the effect of the loading rate was studied. Then the effects of vertical pressure and peak acceleration of ground motion were studied. At last the test results were simulated by the finite element method, and an accurate method to calculate seismic responses of bridges with laminated bearings was proposed.

Keywords: laminated nature rubber bearing, real-time substructure test, loading rate, vertical pressure, numerical simulation.

Introduction. Laminated nature rubber (LNR) bearing is a kind of seismic isolation bearing and often used in civil engineering structures. Advantages of LNR bearings are the large stiffness for vertical loading and small stiffness for lateral loading. Under earthquakes, structural periods of bridges using LNR bearings are longer than those using fixed bearings and seismic forces will be reduced accordingly. LNR bearings were usually combined with dampers to dissipate seismic energy [1].

During the service period, LNR bearing is required to provide sufficient vertical load capacity and lateral displacement capacity. Therefore, the strength and stiffness of LNR bearings were the main research subjects. Square LNR bearings were studied by Koh and Kelly [2], a viscoelastic model was proposed to take the P- $\Delta$ effect into consideration and steady state responses under constant compression stress and sinusoidal horizontal load were obtained. Koo et al. [3] suggested a modified macro model to evaluate the seismic isolation effects of LNR bearing with parameter equations of instantaneous apparent shear modulus. Iizuka [4] proposed a macroscopic model for predicting the large-deformation behaviors of laminated rubber bearings. Tsai and Hsueh [5] proposed a viscoelastic model to study steady state responses of LNR bearing under constant pressure and sinusoidal horizontal load.

Mechanical characteristics of LNR bearings were also studied experimentally. Stanton et al. [6] studied the stability of LNR bearing under different vertical compression stresses. Buckle et al. [7] studied the stability of LNR bearing by a series tests and it was shown that the critical load decreased with increasing shear strain.

Previous test investigations of LNR bearings used mainly static reversed cyclic loading method $[8,9]$. These tests cannot take the loading rate into consideration. However, mechanical properties of LNR bearings have a significant relationship with the loading rate. Therefore, real-time substructure (RTS) testing was proposed to simulate the seismic loading in this paper. Firstly, the test method and setup were introduced. The influence of 
loading rate on seismic responses was studied to prove the necessity of RTS tests. Then influences of vertical pressure and peak acceleration of ground motion were studied. At last test results were simulated by the finite element method, and an accurate method to calculate seismic responses of bridges with LNR bearings was proposed.

1. RTS Test Method. To study the mechanical properties of LNR bearings under earthquakes, seismic tests were suggested. In 1992, the RTS method was introduced by Nakashima et al. [10], which is also referred to as real-time hybrid simulation. It looks like a pseudo dynamic test, but a time step of the test must be completed within a very small increment of time, which allows to investigate structural systems with rate-dependent components by this method $[11,12]$.

In an RTS test, the researched structure is divided into an experimental substructure and a numerical substructure by the substructure technique. The substructure technique is almost the same as that in a pseudo-dynamic test. Usually the interested part of the structure or the part supposed to have significant nonlinear response under seismic loading is taken as an experimental substructure. And the remainder of the structure is taken as a numerical substructure and simulated in the computer. The interface actions between the two substructures are applied by actuators.

Taking a bridge in Fig. 1 as an example to introduce the method, the researched structure is a simply supported bridge with four same LNR bearings. The LNR bearings are selected as the experimental substructure for testing and the girder is selected as the numerical substructure. Two bearings are selected and tested in parallel as shown in Fig. 1.

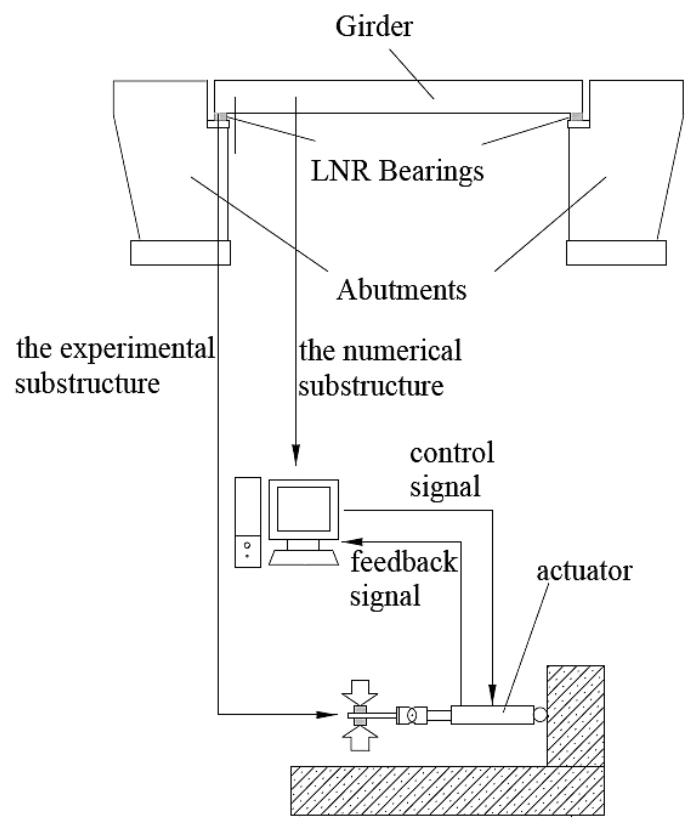

Fig. 1. Schematic diagram of an RTS test.

The bridge structure in Fig. 1 can be simplified as an undamped single-degree of freedom (SDOF) system in Fig. 2, where $M$ represents the girder mass, $K$ represents the nonlinear stiffness of the LNR bearing, which can be measured during the test. The equation of motion of the SDOF system is

$$
M a_{i}+K d_{i}=F_{i},
$$




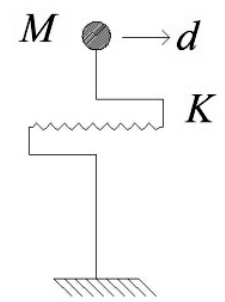

Fig. 2. A simplified SDOF system.

where $a$ and $d$ are acceleration and displacement of the girder, respectively, and $F$ is the seismic force at the time step.

If the central difference method is used in the RTS test, the displacement command at the next time step is calculated with the following equation:

$$
d_{i+1}=2 d_{i}-d_{i-1}-\Delta t^{2}\left(R_{i}-F_{i}\right) / M
$$

where $R$ is the bearing force measured currently.

In the RTS test, $\Delta t$ is required to be as short as possible. Usually a time step less than $0.02 \mathrm{~s}$ can be acceptable. And the velocity and acceleration in the test are regarded to be close to real responses if the displacement command can be applied by the hydraulic servo actuator in the time step.

2. RTS Test Setup. The RTS test was conducted with the MTS FlexTest GT controller in the state key laboratory of disaster reduction in civil engineering, Tongji University. The test setup was composed of a steel frame, a vertical actuator and a horizontal actuator, as shown in Fig. 3. The frame and vertical actuator were fixed on the ground and used to apply the vertical pressure on bearings. One end of the horizontal actuator was fixed on the reaction wall and the other end was connected to a loading plate. The plate was inserted between the two bearings and connected them with bolts. The horizontal actuator drove the plate moving according to the displacement command. The plate displacement was equal to the shear deformation of bearings and the horizontal force of the actuator was equal to twice that of one bearing.

Two same LNR bearings were used in the test. The section of rubber layer is a square with a side length of $400 \mathrm{~mm}$. The thickness of each rubber layer is $10 \mathrm{~mm}$ and the total thickness of rubber layers is $80 \mathrm{~mm}$. The thickness of each steel plate is $3 \mathrm{~mm}$. An LNR bearing is shown in Fig. 4. El-Centro ground motion was used as the input acceleration time history, as shown in Fig. 5.

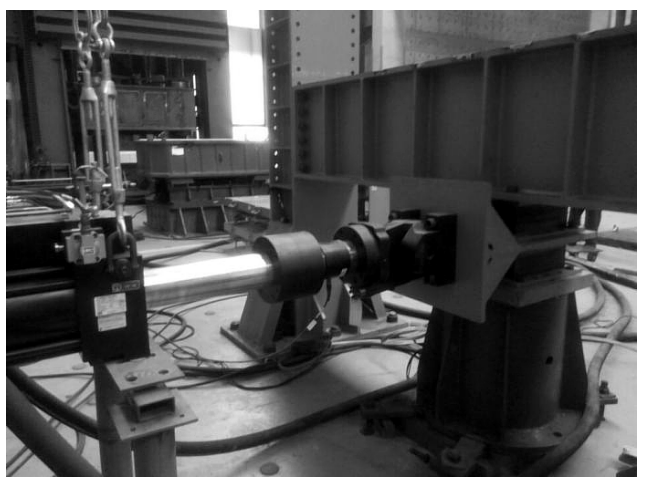

Fig. 3. The RTS test setup.

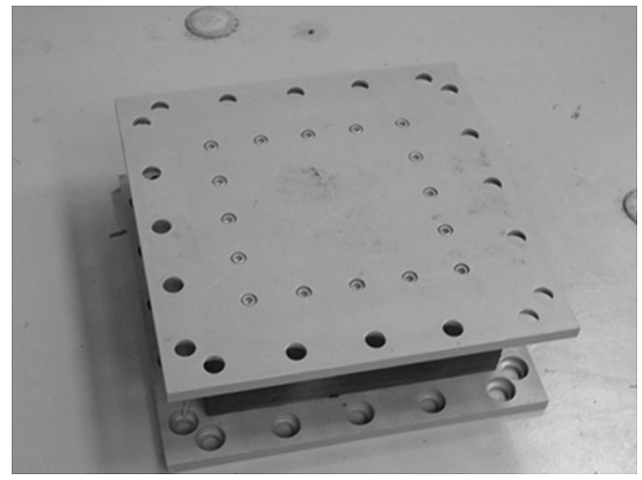

Fig. 4. An LNR bearing used in the RTS test. 


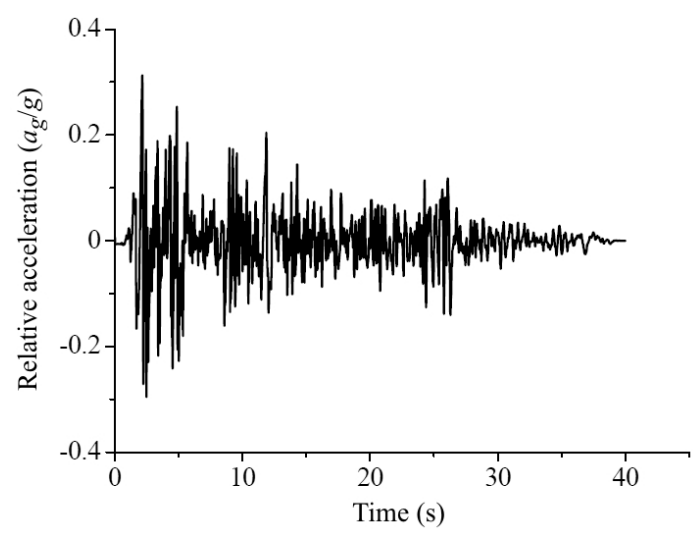

Fig. 5. El-Centro ground motion.

3. The Influence of the Loading Rate. In the RTS test to study the influence of the loading rate, the peak acceleration of El-Centro ground motion was adjusted to $0.2 \mathrm{~g}$. The loading time step $\Delta t_{l}$ was changed and set to be $0.01,0.02,0.025,0.05,0.1$, and $0.2 \mathrm{~s}$, respectively. In the numerical substructure, the real time step of the ground motion was $0.01 \mathrm{~s}$, so only the loading time step of $0.01 \mathrm{~s}$ was real time. The loading rate of the loading time step of $0.02 \mathrm{~s}$ was half of the real loading rate. Likewise, the loading rate of the loading time step of $0.2 \mathrm{~s}$ was $1 / 20$ of the real loading rate. The longer the loading time step is, the slower the loading rate is.

In the test, $M$ was 100 ton and the vertical pressure was $960 \mathrm{kN}$. Bearing displacement time histories and hysteresis curves for different loading rates are shown in Fig. 6. The maximum $F_{\max }$ and minimum $F_{\min }$ bearing forces and maximum $d_{\max }$ and minimum $d_{\text {min }}$ bearing displacements for different loading rates are listed in Table 1. The horizontal equivalent stiffness $K_{e q}$ is calculated according to the following equation:

$$
K_{e q}=\left(F_{\max }-F_{\min }\right) /\left(d_{\max }-d_{\min }\right) .
$$

As shown in Fig. 6, shapes of bearing displacement time histories are similar and hysteresis curves are quite narrow. As shown in Table 1, with the decreasing of the loading rate, bearing displacement will increase and bearing force will decrease. Therefore, the bearing horizontal equivalent stiffness decreases by more than $10 \%$.

$\mathrm{T}$ a b 1 e 1

The Maximum and Minimum Responses for Different Loading Rates

\begin{tabular}{||c|c|c|c|c|c||}
\hline \hline \multirow{2}{*}{$\begin{array}{c}\text { Time } \\
\text { step } \\
(\mathrm{s})\end{array}$} & \multicolumn{2}{|c|}{ Displacement $(\mathrm{mm})$} & \multicolumn{2}{|c|}{ Force $(\mathrm{kN})$} & \multicolumn{2}{c|}{$\begin{array}{c}\text { Horizontal } \\
\text { equivalent stiffness } \\
(\mathrm{kN} / \mathrm{mm})\end{array}$} \\
\cline { 2 - 5 } & $d_{\max }$ & $d_{\min }$ & $F_{\max }$ & $F_{\min }$ & \begin{tabular}{c}
1.85 \\
\hline 0.01
\end{tabular} \\
\hline 0.02 & 59.77 & -60.07 & 113.15 & -108.83 & 1.81 \\
\hline 0.025 & 55.82 & -62.37 & 100.54 & -108.68 & 1.77 \\
\hline 0.05 & 55.23 & -63.12 & 96.22 & -108.25 & 1.73 \\
\hline 0.1 & 56.32 & -65.19 & 94.72 & -109.01 & 1.68 \\
\hline 0.2 & 57.81 & -67.12 & 95.05 & -110.27 & 1.64 \\
\hline
\end{tabular}




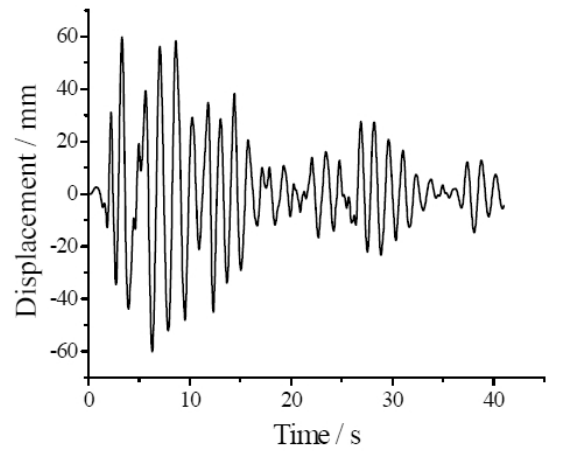

a
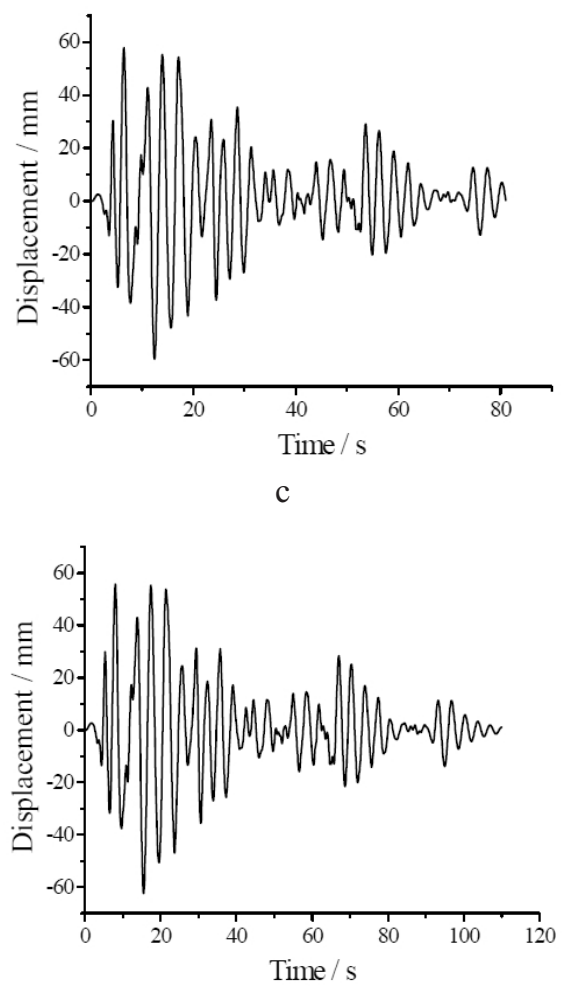

e

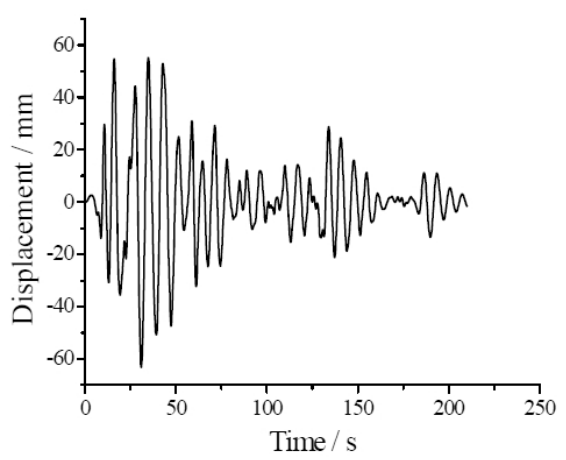

g

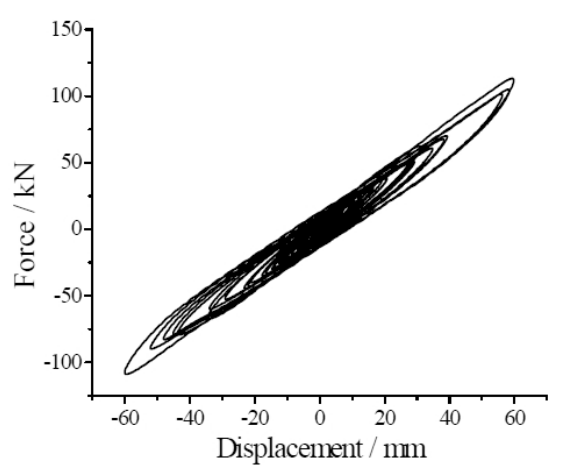

b

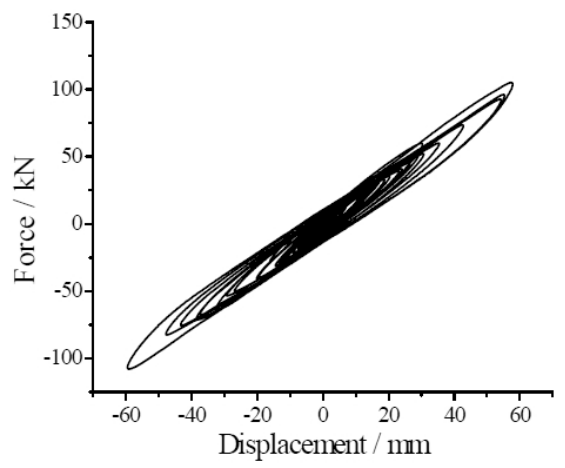

d

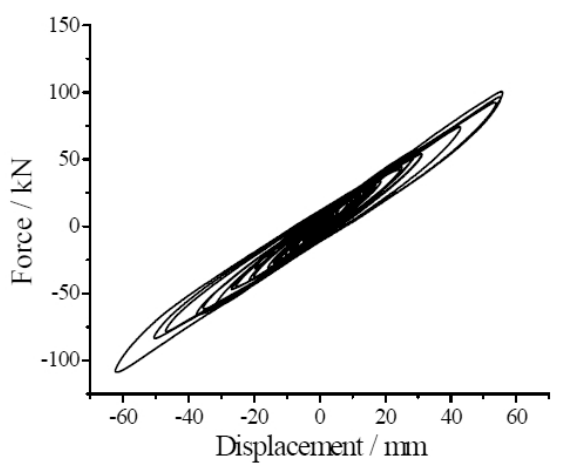

f

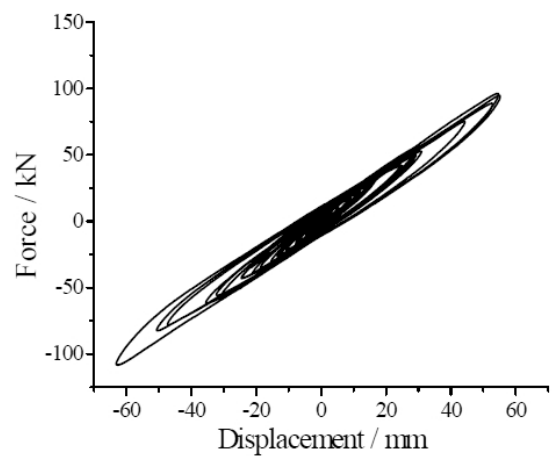

$\mathrm{h}$ 

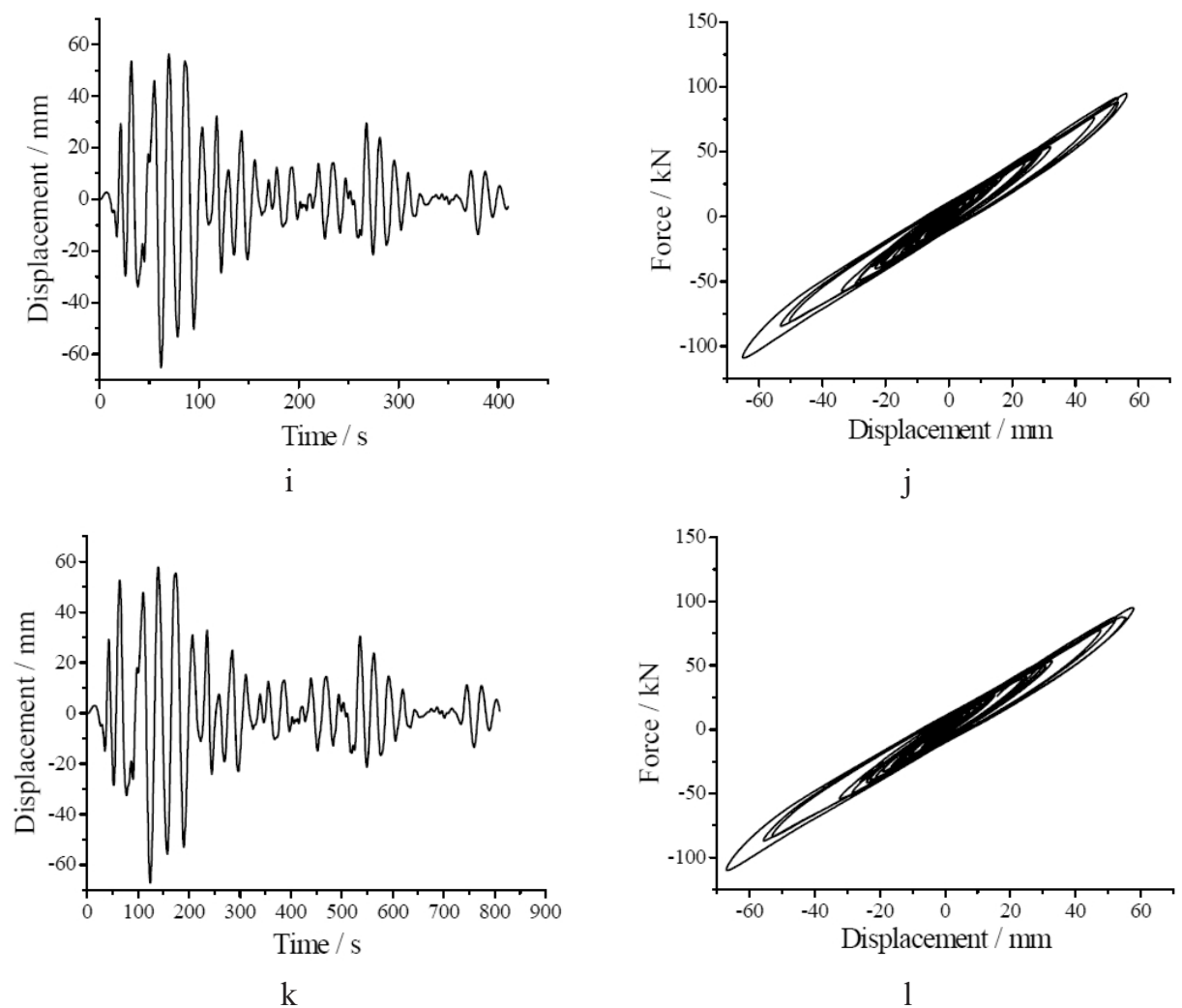

Fig. 6. Test results for different loading rates: displacement time histories (a, c, e, g, i, k) and hysteresis curves (b, d, f, h, j, l) for $\Delta t_{l}=0.01 \mathrm{~s}(\mathrm{a}, \mathrm{b}), 0.02 \mathrm{~s}(\mathrm{c}, \mathrm{d}), 0.025 \mathrm{~s}(\mathrm{e}, \mathrm{f}), 0.05 \mathrm{~s}(\mathrm{~g}, \mathrm{~h}), 0.1 \mathrm{~s}$ $(i, j)$, and $0.2 \mathrm{~s}(\mathrm{k}, \mathrm{l})$.

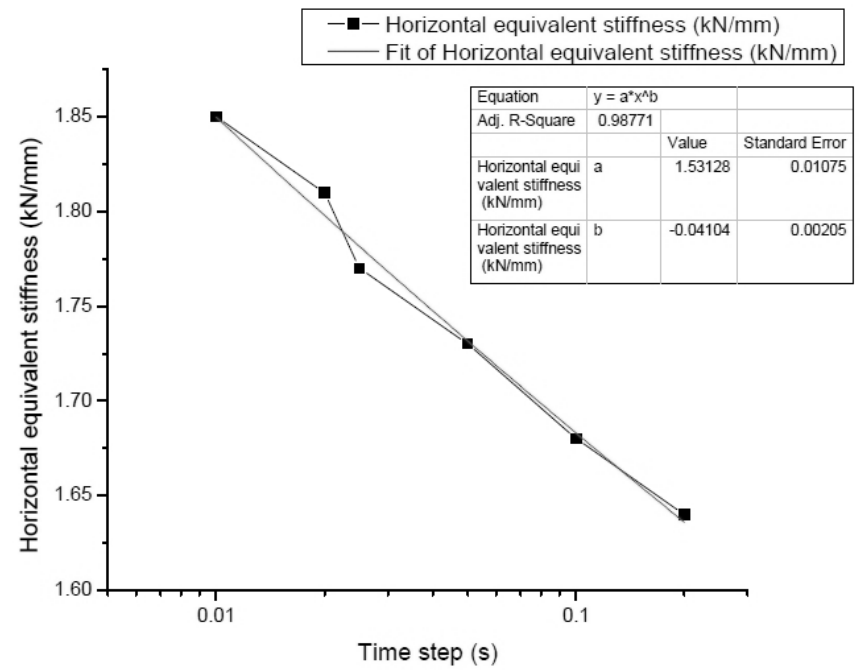

Fig. 7. The relationship between horizontal equivalent stiffness and time step.

The relationship between horizontal equivalent stiffness and time step is shown in Fig. 7. The relationship can be expressed by a simple equation with reasonable accuracy. The adjusted coefficient of determination is 0.98771 . 


$$
K_{e q}=1.53128\left(\Delta t_{l}\right)^{-0.04104}
$$

Slow test cannot take account of the loading rate effect and will underestimate the real horizontal stiffness. To obtain the true seismic responses, a real time loading test method is necessary and the necessity of RTS tests is proven.

4. The Influence of the Vertical Pressure. In the RTS test to study the influence of the vertical pressure, the peak acceleration of El-Centro ground motion was adjusted to $0.2 \mathrm{~g}$. The vertical pressure $N$ was changed and set to be $640,960,1080$, and $1600 \mathrm{kN}$, which correspond to $4,6,8$, and $10 \mathrm{MPa}$. In the test, $M$ was 100 ton and $\Delta t_{l}$ was $0.01 \mathrm{~s}$. Maximum and minimum bearing displacements, maximum and minimum bearing forces for different vertical pressures are listed in Table 2.

$\mathrm{T}$ a b 1 e 2

The Maximum and Minimum Responses for Different Vertical Pressures

\begin{tabular}{|c|c|c|c|c|c||}
\hline \multirow{2}{*}{$\begin{array}{c}\text { Vertical } \\
\text { pressure } \\
(\mathrm{kN})\end{array}$} & \multicolumn{2}{|c|}{ Displacement $(\mathrm{mm})$} & \multicolumn{2}{|c|}{ Force $(\mathrm{kN})$} & \multirow{2}{*}{$\begin{array}{c}\text { Horizontal } \\
\text { equivalent stiffness } \\
(\mathrm{kN} / \mathrm{mm})\end{array}$} \\
\cline { 2 - 5 } & $d_{\max }$ & $d_{\min }$ & $F_{\max }$ & $F_{\min }$ & 1.83 \\
\hline 640 & 61.02 & -58.55 & 113.15 & -105.59 & 1.84 \\
\hline 960 & 60.39 & -60.02 & 112.65 & -108.73 & 1.85 \\
\hline 1080 & 59.48 & -60.60 & 113.38 & -109.32 & 1.87 \\
\hline 1600 & 58.58 & -61.86 & 112.03 & -113.70 & \\
\hline
\end{tabular}

As shown in Table 2, with the increasing of the vertical pressure, bearing displacement will decrease and bearing force will increase. However, the bearing horizontal equivalent stiffness increases very slightly. Therefore, the influence of the vertical pressure is very slightly and can be neglected, at least for the loading rate and peak acceleration in this section.

5. The Influence of the Peak Acceleration. In the RTS test to study the influence of the peak acceleration, the peak acceleration of El-Centro ground motion $a_{g}$ was changed and set to be $0.1 g, 0.15 g, 0.2 g$, and $0.25 g$. In the test, $M$ was 100 ton, $\Delta t_{l}$ was $0.01 \mathrm{~s}$ and $N$ was $960 \mathrm{kN}$. Maximum and minimum bearing displacements, maximum and minimum bearing forces for different peak accelerations are listed in Table 3.

$\mathrm{T}$ a $\mathrm{b} 1$ e 3

The Maximum and Minimum Responses for Different Peak Accelerations

\begin{tabular}{||c|c|c|c|c|c||}
\hline \multirow{2}{*}{$\begin{array}{c}\text { Peak } \\
\text { acceleration }\end{array}$} & \multicolumn{2}{|c|}{ Displacement $(\mathrm{mm})$} & \multicolumn{2}{|c|}{ Force $(\mathrm{kN})$} & \multirow{2}{*}{$\begin{array}{c}\text { Horizontal } \\
\text { equivalent stiffness } \\
(\mathrm{kN} / \mathrm{mm})\end{array}$} \\
\cline { 2 - 5 } & $d_{\max }$ & $d_{\min }$ & $F_{\max }$ & $F_{\min }$ & 1.93 \\
\hline $0.1 g$ & 30.54 & -29.80 & 61.19 & -55.28 & 1.92 \\
\hline $0.15 g$ & 47.93 & -42.08 & 92.67 & -79.96 & 1.84 \\
\hline $0.2 g$ & 60.39 & -60.02 & 112.65 & -108.73 & 1.93 \\
\hline $0.25 g$ & 75.34 & -76.15 & 146.68 & -145.62 & \\
\hline
\end{tabular}

As shown in Table 3, with the increasing of the peak accelerations, bearing displacement and bearing force will increase both. The bearing horizontal equivalent stiffness decreases a little (nearly 5\%) at first and then increases a little (nearly 5\%). 
Generally, the influence of the peak acceleration is very slightly and can be neglected. Note that, the maximum shear strain in the test was less than $100 \%$, and if the shear strain is greater than $100 \%$, the nonlinearity might have to be considered.

6. Numerical Simulation. The finite element software SAP2000 is used to compare calculated results with different simulation methods and test results. The undamped SDOF system in Fig. 2 is taken as an example to calculate the bridge seismic responses.

The first simulation method is suggested in current seismic design standards, where LNR bearings are usually suggested to be simulated with linear springs [13]. In the analysis, $M$ is 100 ton, El-Centro ground motion with $a_{g}$ of $0.2 g$ was input. The stiffness of the LNR bearing is $1.84 \mathrm{kN} / \mathrm{mm}$ according to test results. Bearing displacement time histories and hysteresis curves of test and calculated results are compared in Fig. 8. Solid lines in the figure are test results, and dashed lines are calculated results.

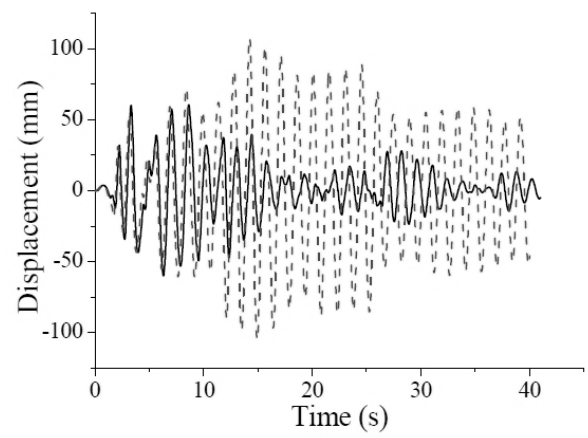

a

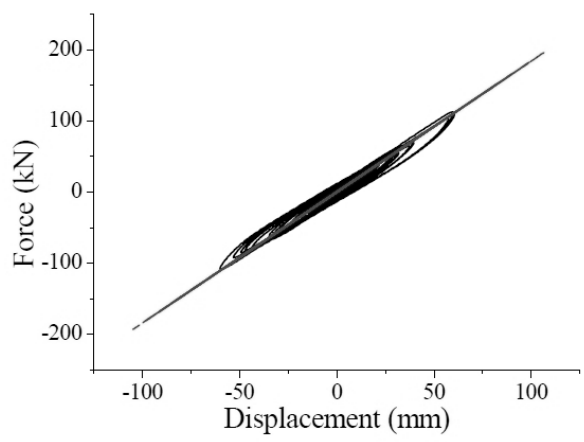

b

Fig. 8. Comparisons of test and calculated results with linear springs: displacement time history (a) and hysteresis curve (b) for $a_{g}=0.2 g$.

As shown, without respect to the damping, the simulation of LNR bearings with linear springs can overestimate the seismic responses greatly. Even if the energy dissipation capacities of LNR bearings are small usually, it is important to simulate the damping accurately.

The second simulation method is suggested in this paper, where the LNR bearing is simulated with a linear spring and a linear viscous damper. The stiffness of the LNR bearing is $1.84 \mathrm{kN} / \mathrm{mm}$, and the damping ratio can be chosen to be $3.5 \%$ according to test results. The bearing displacement time histories and hysteresis curves of test and calculated results are compared in Fig. 9. As shown, the seismic responses are simulated accurately.

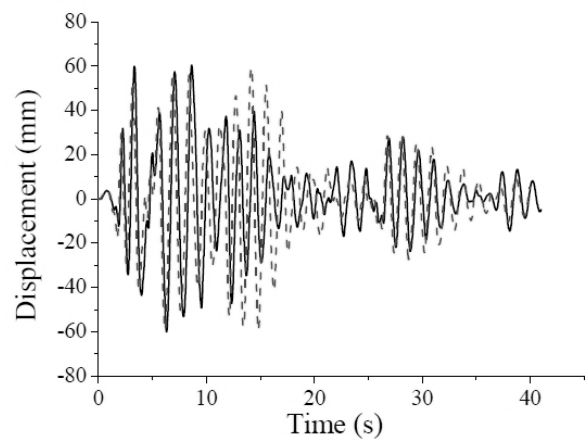

a

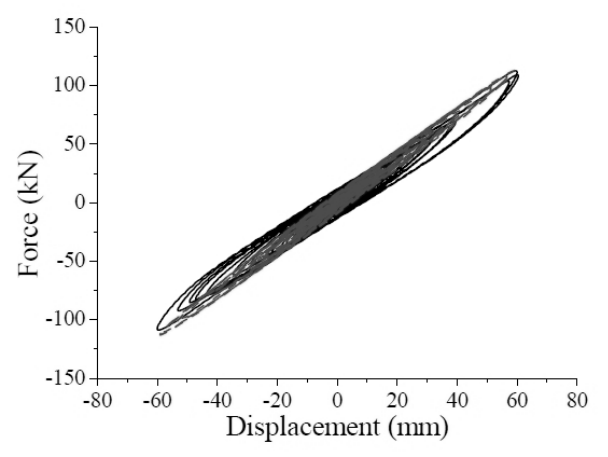

b

Fig. 9. Comparisons of test and calculated results with linear springs and dampers: displacement time history (a) and hysteresis curve (b) for $a_{g}=0.2 \mathrm{~g}$. 
Real-Time Substructure Tests and Numerical Simulation ...

$\mathrm{T}$ a b 1 e 4

Comparisons of Test and Calculated Results

\begin{tabular}{|c|c|c|c|c|c|c|c||}
\hline \multirow{3}{*}{$\begin{array}{c}\text { Peak } \\
\text { acceleration }\end{array}$} & \multirow{2}{*}{$\max / \mathrm{min}$} & \multicolumn{3}{|c|}{ Displacement $(\mathrm{mm})$} & \multicolumn{3}{c|}{ Force $(\mathrm{kN})$} \\
\cline { 3 - 8 } & & Test & Calculated & $\begin{array}{c}\text { Error } \\
(\%)\end{array}$ & Test & Calculated & $\begin{array}{c}\text { Error } \\
(\%)\end{array}$ \\
\hline \multirow{2}{*}{$0.1 g$} & $\max$ & 30.54 & 29.66 & -2.87 & 61.19 & 56.45 & -7.75 \\
\cline { 2 - 9 } & $\min$ & -29.80 & -29.66 & -0.45 & -55.28 & -56.47 & 2.15 \\
\hline \multirow{2}{*}{$0.15 g$} & $\max$ & 47.93 & 44.49 & -7.18 & 92.67 & 84.67 & -8.63 \\
\cline { 2 - 9 } & $\min$ & -42.08 & -44.49 & 5.72 & -79.96 & -84.71 & 5.94 \\
\hline \multirow{2}{*}{$0.2 g$} & $\max$ & 60.39 & 59.32 & -1.77 & 112.65 & 112.90 & 0.22 \\
\cline { 2 - 9 } & $\min$ & -60.02 & -59.32 & -1.17 & -108.73 & -112.95 & 3.88 \\
\hline \multirow{2}{*}{$0.25 g$} & $\max$ & 75.34 & 74.15 & -1.57 & 146.68 & 141.12 & -3.79 \\
\cline { 2 - 8 } & $\min$ & -76.15 & -74.15 & -2.63 & -145.62 & -141.18 & -3.05 \\
\hline
\end{tabular}

For different peak accelerations, maximum and minimum bearing displacements, maximum and minimum bearing forces of test and calculated results are compared and listed in Table 4. As shown, test and calculated results match well with each other. All the errors are less than $10 \%$ and most of them are less than $5 \%$.

Conclusions. The seismic responses and simulation of LNR bearings are studied using RTS tests and FEM analysis, and the following conclusions can be drawn:

1. Slow test cannot take account of the loading rate effect and real-time loading test methods are necessary to obtain the real seismic responses.

2. The influence of the vertical pressure is very slightly and can be neglected, at least for the real loading rate and peak acceleration in this paper.

3. If the shear strain $<100 \%$, the influence of the peak acceleration is very slightly and can be neglected.

4. The simulation of an LNR bearing with a linear spring can overestimate the seismic responses greatly, so it is important to simulate the damping accurately.

5. After considering a damping ratio of $3.5 \%$, the test and calculated results match well with each other, so the simulation of an LNR bearing with a linear spring and a damper can estimate seismic responses accurately.

Acknowledgments. This work was supported in part by the National Natural Science Foundation of China (No. 51278372) and the Ministry of Science and Technology of China, Grant No. SLDRCE 14-B-15.

1. Guide Specifications for Seismic Isolation Design, 3rd edn, American Association of State Highway and Transportation Officials, Washington, DC (2010).

2. C. G. Koh and J. M. Kelly, Effects of Axial Load on Elastomeric Isolation Bearings, Report No. UCB/EERC-86/12, Earthquake Engineering Research Center, University of California, Berkeley (1986).

3. G. H. Koo, J. H. Lee, B. Yoo, and Y. Ohtori, "Evaluation of laminated rubber bearings for seismic isolation using modified macro model with parameter equations of instantaneous apparent shear modulus," Eng. Struct., 21, No. 7, 594-602 (1999).

4. M. Iizuka, "A macroscopic model for predicting large-deformation behaviors of laminated rubber bearings," Eng. Struct., 22, No. 4, 323-334 (2000). 
5. H. C. Tsai and S. J. Hsueh, "Mechanical properties of isolation bearings identified by a viscoelastic model," Int. J. Solids Struct., 38, No. 1, 53-74 (2001).

6. J. F. Stanton, G. Scroggins, A. W. Taylor, and C. W. Roeder, "Stability of laminated elastomeric bearings," J. Eng. Mech., 116, No. 6, 1351-1371 (1990).

7. I. Buckle, S. Nagarajaiah, and K. Ferrell, "Stability of elastomeric isolation bearings: experimental study," J. Struct. Eng., 28, No. 1, 3-11 (2002).

8. S. K. Jain and S. K. Thakkar, "Quasi-static testing of laminated rubber bearings," $J$. Inst. Eng. (India): Civil Eng. Div., 84, 110-115 (2003).

9. I. Gjorgjiev and M. Garevski, "A polynomial analytical model of rubber bearings based on series of tests," Eng. Struct., 56, 600-609 (2013).

10. M. Nakashima, H. Kato, and E. Takaoka, "Development of real-time pseudo dynamic testing," Earthq. Eng. Struct. Dynam., 21, No. 1, 79-92 (1992).

11. T. Asai, C.-M. Chang, B. M. Phillips, and B. F. Spences, "Real-time hybrid simulation of a smart outrigger damping system for high-rise buildings," Eng. Struct., 57, 177-88 (2013).

12. B. Wu, Z. Wang, and O. S. Bursi, "Actuator dynamics compensation based on upper bound delay for real-time hybrid simulation," Earthq. Eng. Struct. Dynam., 42, No. 12, 1749-1765 (2013).

13. JTG/T B02-01-2008. Guidelines for Seismic Design of Highway Bridges, Chinese Standard, Implemented on October 1, 2008.

Received 15. 09. 2017 